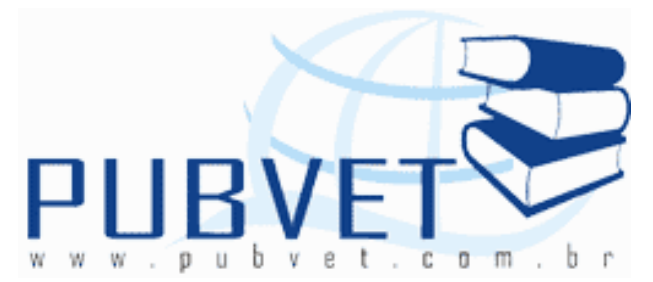

PUBVET, Publicações em Medicina Veterinária e Zootecnia.

\title{
Efeito dos equipamentos utilizados em touros de rodeio
}

André Luiz Quagliatto Santos ${ }^{1}$; Thaís Carneiro Santos Rodrigues ${ }^{2}$; Natália Siqueira D'Aparecida2; Omar Teodoro Silva Júnior3; Flávio Machado de Moraes $^{3}$; Mariana Rodrigues Moreira ${ }^{4}$; Patrícia Massuda ${ }^{4}$

1. Professor Titular da Faculdade de Medicina Veterinária, Universidade Federal de Uberlândia-UFU 2. Graduandos da Faculdade de Medicina Veterinária, Universidade Federal de Uberlândia-UFU 3. Mestrando da Faculdade de Medicina Veterinária, Universidade Federal de Uberlândia-UFU 4. Médicas Veterinárias

\section{Resumo}

Realizou-se pesquisa bibliográfica e pesquisa de campo em rodeios do estado de Minas Gerais com o objetivo de analisar os efeitos dos equipamentos (sedém, corda americana e esporas), utilizados nos touros durante a prática do rodeio, bem como analisar o próprio equipamento fazendo mensurações dos mesmos, identificar as regiões do corpo do animal que mais sofrem lesões durante a montaria e ainda verificar se existe alguma relação entre o lado de queda dos peões, a mão que o peão segura e o sentido do giro do touro durante a montaria com o lado do corpo do animal em que ocorreram as lesões. Foram observados 231 animais após a montaria. Observou-se que $68,80 \%$ dos animais não sofreram nenhum tipo de lesão devido ao uso dos equipamentos. A região que mais apresentou lesões foi a região do costado. 
SANTOS, A.L.Q. et al. Efeito dos equipamentos utilizados em touros de rodeio. PUBVET, Londrina, V. 5, N. 24, Ed. 171, Art. 1156, 2011.

Os resultados mostraram ainda que, estatisticamente, não existe nenhum tipo de relação entre o lado de queda dos peões, a mão que o peão segura e o sentido do giro do touro durante a montaria com o lado em que houve lesões nos animais.

Palavras-chave: rodeio, equipamentos, touros

\section{Effects of the equipments used in rodeo bulls}

\section{Abstract}

A literature review and field research were made in rodeos in the state of Minas Gerais to analyze the effects of equipment (sedém, American rope and spurs), used in rodeo bulls during practice, and analyze their own equipment doing the same measurements, to identify regions of the animal's body that suffer the most injuries while riding and also assess whether there is any relationship between the side of falling for pedestrians, the hand that holds the pawn and the direction of rotation during the bull riding with the side of the animal body where injuries occurred. 231 animals were observed in rodeos after riding in the back and it was observed that $68.80 \%$ of the analyzed animals have not suffered any injury due to use of equipment. The region that showed more lesions were from the sidewalls, which may be due to the region of greatest contact between animal and pedestrian. The results also showed that statistically there is no relationship between the side of falling for pedestrians, the hand that holds the pawn and the direction of rotation during the bull riding with the side on which there was injury to animals.

Keywords: rodeo, equipments, bulls

\section{INTRODUÇÃO}

Segundo Resolução no 18 da Secretaria de Agricultura e Abastecimento do Estado de São Paulo, de 31 de março de 1998, os rodeios vêm assumindo papel relevante na geração de empregos e renda no interior, havendo a 
SANTOS, A.L.Q. et al. Efeito dos equipamentos utilizados em touros de rodeio. PUBVET, Londrina, V. 5, N. 24, Ed. 171, Art. 1156, 2011.

necessidade de adequada regulamentação das atividades de rodeio de animais, favorecendo a preservação da sua integridade física (SÃO PAULO, 1998).

Para que haja proteção da integridade física dos animais foi criada a Lei no 10.519, de 17 de Julho de 2002, que de acordo com o Artigo 30, parágrafo II, diz que a entidade promotora do rodeio deverá providenciar médico veterinário habilitado, responsável pela garantia da boa condição física e sanitária dos animais e pelo cumprimento das normas disciplinadoras, impedindo maus tratos e injúrias de qualquer ordem (BRASIL, 2002).

Durante a montaria são utilizados os seguintes equipamentos: espora, sedém e corda americana. O sedém é uma corda feita de lã ou com fios do rabo do cavalo amarrada na virilha do animal. É usada para estimular os pulos. Não machuca, apenas incomoda. Corda Americana é o acessório que envolve o tórax do animal onde o peão segura com a mão de apoio. Feita de náilon ou rami (fibra vegetal), é trançada manualmente e recebe breu para possibilitar maior aderência ao segurá-la com luva (O PORTAL..., 2004). De acordo com Torres (2000), espora é um instrumento de metal articulado à bota por intermédio do qual o cavaleiro incita o animal, porém não é permitido que tenha pontas capazes de feri-lo. O presente trabalho buscou estudar os efeitos destes equipamentos, além de caracterizar o uso da corda americana e do sedém em relação ao bem estar animal e o uso de esporas com a ocorrência de lesões ocasionadas pelas mesmas; como também associar o lado de queda do peão, a mão que o peão segura e o sentido do giro do touro com as lesões no corpo do animal em relação aos lados direito e esquerdo, bem como suas respectivas freqüências e relações com as regiões do corpo do animal.

\section{MATERIAL E MÉTODO}

Observaram-se o total de 231 touros em rodeios no ano de 2005, nos municípios de Monte Alegre de Minas, Uberaba, Uberlândia e Ibiá, todos no estado de Minas Gerais.

As lesões ocorridas nos animais foram observadas em ambos os lados do corpo do touro com auxílio de lanternas no retorno (local por onde os touros passam 
SANTOS, A.L.Q. et al. Efeito dos equipamentos utilizados em touros de rodeio. PUBVET, Londrina, V. 5, N. 24, Ed. 171, Art. 1156, 2011.

após a montaria) e foram anotadas em fichas contendo os nomes dos touros e o desenho dos lados direito e esquerdo das lesões (retratando o tamanho e local das lesões) causadas devido ao uso dos equipamentos. Outras fichas continham o nome do peão e nome do touro a ser montado, e foram utilizadas para observação do lado de queda dos peões, sentido do giro do touro e mão que o peão segura (direita ou esquerda) durante a montaria para a realização do tratamento estatístico aplicando-se o teste do qui-quadrado a fim de associar o lado da queda, mão que o peão segura no touro e sentido do giro do touro com o lado em que ocorreram lesões e ainda em que região do corpo do animal essas lesões ocorreram.

Para facilitar a análise dos dados, estes foram subdivididos em: lesão do lado esquerdo do corpo do animal/lesão do lado direito do corpo do animal; lado de queda dos peões/lesões do lado esquerdo do corpo do animal; lado de queda dos peões/lesões do lado direito do corpo do animal; mão que o peão segura durante a montaria/ lesões do lado esquerdo do corpo do animal; mão que o peão segura durante a montaria/ lesões do lado direito do corpo do animal; sentido do giro do touro durante a montaria/ lesões do lado esquerdo do corpo do animal e sentido do giro do touro durante a montaria/ lesões do lado direto do corpo do animal.

As medidas das esporas e cordas americanas foram realizadas antes do início do rodeio, com o auxílio de um paquímetro, trena com precisão em milímetros e fichas de anotação. Houve resistência da maioria dos peões e apenas 76 peões disponibilizaram seus equipamentos para a realização da pesquisa. Foram verificadas as medidas do diâmetro, espessura e largura da roseta das esporas (Figura 1). Na corda americana, foram realizadas mensurações de diâmetro da corda da barrigueira, sendo que esta medida foi multiplicada por quatro para se obter a largura total do equipamento, em contato com o animal (Figura 2).

Os dados foram anotados para análise estatística, cálculo da média, desvio padrão e intervalo de confiança. 


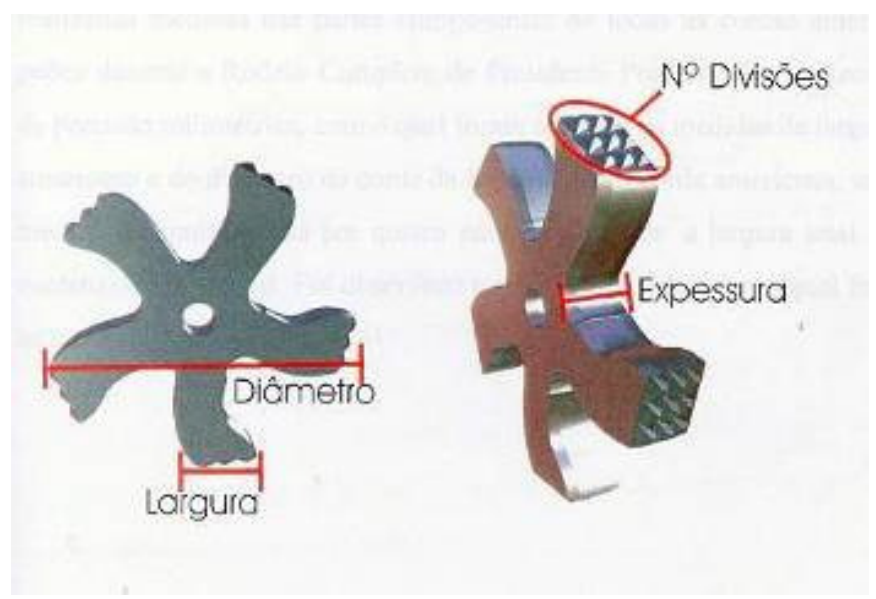

Figura 1- Espora.

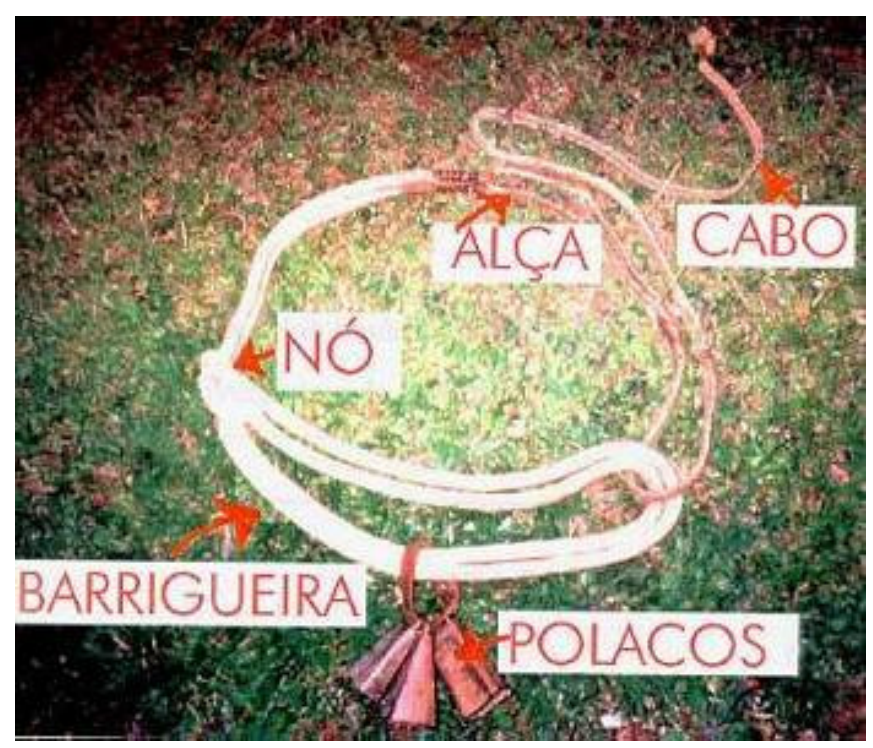

Figura 2- Corda americana e suas partes.

Analisar o sedém durante o rodeio é uma tarefa difícil, devido à rapidez em que ocorre a preparação do touro para a montaria. Devido a este fato, para que o mesmo fosse analisado foi necessária a colaboração de um tropeiro em Ibiá, que dispôs-se a fechar seus animais pela manhã, colocá-los no brete e colocar os sedéns em cada um dos animais. Assim, foram analisados 14 touros todos utilizando o mesmo sedém. Registrou-se com o uso de uma fita métrica a circunferência feita pelo sedém ao redor do animal antes e depois de ser 
SANTOS, A.L.Q. et al. Efeito dos equipamentos utilizados em touros de rodeio. PUBVET, Londrina, V. 5, N. 24, Ed. 171, Art. 1156, 2011.

apertado, entre as argolas de aperto e da espessura da parte principal (Figura $3)$.

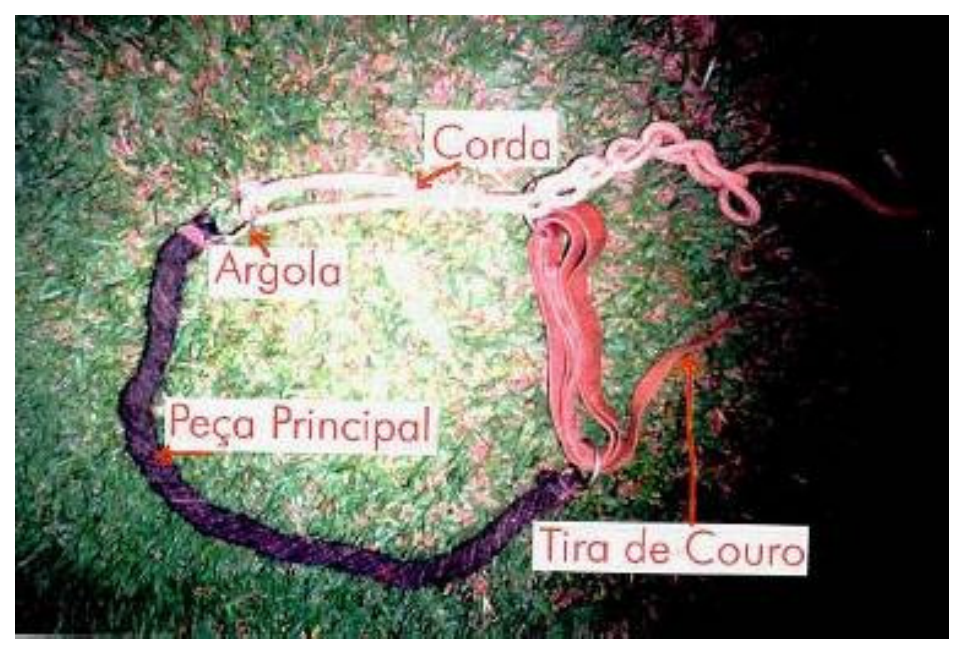

Figura 3- Sedém e as partes que o compõem.

\section{RESULTADOS E DISCUSSÃO}

Tabela 1- Medidas da corda americana realizadas em rodeios de Minas Gerais no ano de 2005.

\begin{tabular}{l|l|l}
\hline & $\begin{array}{l}\text { ESPESSURA DA } \\
\text { CORDA } \\
\text { DA BARRIGUEIRA }\end{array}$ & $\begin{array}{l}\text { ESPESSURA TOTAL } \\
\text { DA BARRIGUEIRA }\end{array}$ \\
\hline Média (cm) & 1,32 & 5,3 \\
Desvio Padrão (cm) & 0,27 & 1,05 \\
Intervalo de confiança & 1,$25 ; 1,38$ & 5,$06 ; 5,55$ \\
$(95.0 \%)(\mathrm{cm})$ & 76 & 76 \\
Contagem & \\
\hline Espera-se, com 95\% de confiança, que a média da espessura da corda da \\
barrigueira esteja contida entre 1,25 cm e 1,38 cm. A espessura total da \\
barrigueira, com a confiança de 95\%, está contida entre 5,06 cm e 5,55 cm.
\end{tabular}


SANTOS, A.L.Q. et al. Efeito dos equipamentos utilizados em touros de rodeio. PUBVET, Londrina, V. 5, N. 24, Ed. 171, Art. 1156, 2011.

Tabela 2- Medidas da espora realizadas em rodeios em Minas Gerais no ano de 2005

\begin{tabular}{l|l|l|ll}
\hline & DIÂMETRO & ESPESSURA & $\begin{array}{l}\text { LARGURA } \\
\text { PONTA }\end{array}$ \\
\hline Média (cm) & 2,57 & 0,22 & 0,45 \\
Desvio Padrão (cm) & 0,16 & 0,08 & 0,10 \\
Intervalo de confiança & 2,$51 ; 2,61$ & 0,$20 ; 0,24$ & 0,$39 ; 0,43$ \\
$(95.0 \%)(\mathrm{cm})$ & & & \\
Contagem & 76 & 76 & 76 \\
\hline
\end{tabular}

Espera-se, com 95\% de confiança, que a média do diâmetro das esporas esteja entre $2,51 \mathrm{~cm}$ e $2,61 \mathrm{~cm}$. A média da espessura das esporas, com $95 \%$ de confiança, está contida entre e $0,20 \mathrm{~cm}$ e $0,24 \mathrm{~cm}$. No que diz respeito à largura da ponta das esporas, com 95\% de confiança, pode-se afirmar que a média está contida entre $0,39 \mathrm{~cm}$ e $0,43 \mathrm{~cm}$.

Tabela 3- Medidas do sedém realizada em simulação de um rodeio no município de Ibiá-MG no ano de 2005.

\begin{tabular}{l|l|l|l}
\hline & $\begin{array}{l}\text { ANTES DO } \\
\text { APERTO }\end{array}$ & $\begin{array}{l}\text { DEPOIS DO } \\
\text { APERTO }\end{array}$ & DIFERENÇA \\
\hline Média (m) & 2,17 & 2,07 & 0,12 \\
Desvio Padrão $(\mathrm{m})$ & 0,11 & 0,10 & 0,05 \\
Intervalo de confiança & 2,$11 ; 2,23$ & 2,$00 ; 2,12$ & 0,$08 ; 0,14$ \\
$(95.0 \%)(\mathrm{m})$ & & & \\
Contagem & 14 & 14 & 14 \\
\hline
\end{tabular}

Antes do aperto, espera-se com 95\% de confiança, que a média do sedém esteja contida entre $2,11 \mathrm{~m}$ e 2,23 m. Depois do aperto, espera-se com $95 \%$ de confiança, que a média do sedém esteja contida entre $2,00 \mathrm{~m}$ e 2,12 m. O intervalo de confiança de $95 \%$ para a diferença entre antes de depois foi de 
SANTOS, A.L.Q. et al. Efeito dos equipamentos utilizados em touros de rodeio. PUBVET, Londrina, V. 5, N. 24, Ed. 171, Art. 1156, 2011.

$0,08 \mathrm{~m}$ a $0,14 \mathrm{~m}$, indicando que estatisticamente existe diferença significativa entre os momentos antes e depois do aperto do sedém.

Avaliou-se a freqüência das lesões ocorridas por esporas nos lados direito e esquerdo do corpo do animal e sua relação com a região do corpo em que ocorreram essas lesões por meio da aplicação do teste do qui-quadrado. A associação entre as lesões por esporas que ocorreram nos lados direito e esquerdo do corpo do animal e suas relações com a região do corpo em que ocorreram, não é significativo ( $p$-valor $=0,10$ ), onde o valor do qui-quadrado calculado é 0,895.

A avaliação da freqüência das lesões ocorridas por esporas do lado esquerdo do touro e suas correlações com as regiões do corpo do animal em relação ao lado de queda do peão, também realizada através do teste do qui-quadrado, foi considerada não significativa ( $p$-valor $=0,10$ ), onde o valor do quiquadrado calculado é 0,322 . Já a associação entre o lado queda dos peões e as lesões por esporas que ocorreram no lado direito do corpo do animal e suas relações com a região do corpo em que ocorreram, não é significativo ( $p$-valor $=0,10)$, onde o valor do qui-quadrado calculado é 0,911 .

$\mathrm{Na}$ aplicação do teste do qui-quadrado, a associação entre a mão que o peão segura durante a montaria e as lesões por esporas que ocorreram no lado esquerdo do corpo do animal e suas relações com a região do corpo em que ocorreram, não é significativo ( $p$-valor $=0,10$ ), onde o valor do qui-quadrado calculado é 0,705.

A associação entre a mão que o peão segura durante a montaria e as lesões por esporas que ocorreram no lado direito do corpo do animal e suas relações com a região do corpo em que ocorreram, não é significativo ( $p$-valor $=0,10$ ), onde o valor do qui-quadrado calculado é 0,794.

$\mathrm{Na}$ aplicação do teste do qui-quadrado, a associação entre o sentido do giro do touro durante a montaria e as lesões por esporas que ocorreram no lado esquerdo do corpo do animal e suas relações com a região do corpo em que ocorreram, não é significativo ( $p$-valor $=0,10$ ), onde o valor do qui-quadrado calculado é 0,993. 
SANTOS, A.L.Q. et al. Efeito dos equipamentos utilizados em touros de rodeio. PUBVET, Londrina, V. 5, N. 24, Ed. 171, Art. 1156, 2011.

Na aplicação do teste do qui-quadrado, a associação entre o sentido do giro do touro durante a montaria e as lesões por esporas que ocorreram no lado direito do corpo do animal e suas relações com a região do corpo em que ocorreram, não é significativo ( $p$-valor $=0,10$ ), onde o valor do qui-quadrado calculado é 0,132 .

Em relação ao total de lesões, dos 231 animais observados, apenas 31,20\% dos animais sofreram lesões no corpo devido ao uso da espora, sendo que a maioria dos animais, $68,80 \%$ não apresentou nenhum tipo de lesão. Não foram observadas lesões aparentes devido ao uso da corda americana e do sedém. Os resultados encontrados estão de acordo com SÃO PAULO (1998), artigo 90, que proíbe o uso de barrigueiras que causem lesões nos animais. Nenhum dos animais examinados apresentou algum tipo de lesão devido ao uso da corda americana. Com 95\% de confiança, pode-se afirmar que a média da espessura da barrigueira está contida entre 5,06 cm e 5,55 cm (Tabela 1), o que indica ser uma espessura que não irá ferir o tórax do animal, apesar da espessura não ser padronizada e sim o material da qual a corda é confeccionada.

Os resultados mostraram que com uma confiança de $95 \%$ a diferença entre antes e depois do aperto do aperto do sedém apresenta média contida entre

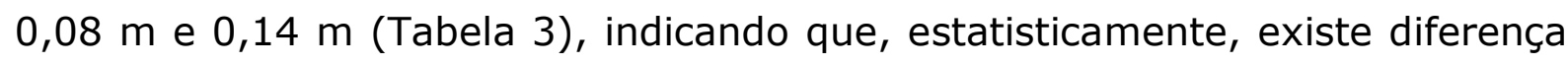
entre os momentos de antes e depois do aperto, o que seria, portanto, indicativo de incomodo ou mesmo capaz de lesar os animais. No entanto, não foram encontradas nenhum tipo de lesão nos animais analisados e os sedéns demonstraram serem confeccionados de material macio como a lã, o que está de acordo com SÃO PAULO (1998).

Os resultados estão de acordo com VASCONCELOS et al. (2000), que relata não haver qualquer relação do sedém com os testículos dos animais, e que as biópsias, realizadas na região de contato com o sedém, demonstraram a ausência de lesões histopatológicas.

Os resultados das esporas estão de acordo com SÃO PAULO (1998), uma vez que não foram encontrados objetos pontiagudos nas mesmas e também estão de acordo com (CONFEDERAÇÃO, 2005), que afirma que as rosetas utilizadas 
SANTOS, A.L.Q. et al. Efeito dos equipamentos utilizados em touros de rodeio. PUBVET, Londrina, V. 5, N. 24, Ed. 171, Art. 1156, 2011.

pelos competidores, em rodeios fiscalizados pela Confederação Nacional de Rodeio (CNAR), não têm pontas. Tais fatos discordam de CHEBADI (2000), que relata serem as esporas, metais pontiagudos que são usados pelos peões durante o rodeio, fincados no baixo ventre, cabeça e pescoço dos animais. Dos animais observados $68,80 \%$ não sofreram lesões devido ao uso da espora. Tais resultados discordam de TORMEM (1999), que relata que $65,85 \%$ dos animais no Rodeio Universitário de Uberaba-98 sofreram lesões.

No que diz respeito às medidas das esporas foi encontrada uma diferença significativa em relação às medidas de diâmetro, espessura e largura da ponta (Tabela 2), o que mostra que, embora haja uma padronização feita pela Confederação Nacional de Rodeio, as esporas mensuradas neste trabalho não estão padronizadas. É importante ressaltar que a maioria dos peões não permitiu a análise de seus equipamentos.

Quando se compara as freqüências das lesões que ocorreram do lado esquerdo do corpo do animal, com as que ocorreram do lado direito, em relação às regiões do corpo do animal em que essas lesões ocorreram, observamos que nos 20 casos não houve lesões do lado direito do corpo do animal (SL) e que houve lesões na região do costado (C) no lado esquerdo do corpo do animal. Tais observações correspondem a $71,4 \%$ do total das lesões observadas na região do costado $(C)$ do lado esquerdo do corpo do animal; $10,4 \%$ do total de sem lesões (SL) do lado direito do corpo do animal e a 8,7\% dos 231 animais observados.

O maior número de observações feitas de ambos os lados, direito e esquerdo, corresponde à SL (sem lesão), onde foram realizadas 159 observações em que não houve lesões em nenhum dos lados do corpo dos animais. Este número corresponde a $85 \%$ do total dos animais que não tiveram nenhuma lesão do lado esquerdo do corpo; $82,4 \%$ dos que não tiveram lesões do lado direito do corpo e a $68,8 \%$ dos animais que não tiveram lesões em nenhum dos lados do corpo.

De acordo com a aplicação do teste do qui-quadrado, a associação entre as lesões por esporas que ocorreram nos lados direito e esquerdo do corpo do 
SANTOS, A.L.Q. et al. Efeito dos equipamentos utilizados em touros de rodeio. PUBVET, Londrina, V. 5, N. 24, Ed. 171, Art. 1156, 2011.

animal e suas relações com a região do corpo em que ocorreram, não é significativo ( $p$-valor $=0,10$ ), onde o valor do qui-quadrado calculado é 0,895 . Ao observar o lado de queda que os peões caem durante a montaria em relação às lesões que ocorreram do lado esquerdo do corpo do animal, notouse que a maioria das lesões ocorreu na região do costado (C), 13 observações, quando os peões caíam do lado esquerdo do animal. Esses dados correspondem a $17,1 \%$ do total de peões que caíram do lado esquerdo e que os animais tiveram lesões na região do costado do lado esquerdo; $46,4 \%$ do total de lesões observadas na região do costado (C) do lado esquerdo do corpo do animal e a 5,6\% dos 231 animais que tiveram lesões na região do costado (C) do lado esquerdo do corpo quando os peões caíam do seu lado esquerdo. Quando comparado o lado de queda dos peões com as lesões encontradas no lado direito do corpo dos animais, a maioria das lesões também ocorreu na região do costado (C), no entanto quando os peões caíam do lado direito do animal. Foram feitas 13 observações correspondem a 9,9\% do total de peões que caíram do lado direito; $59,1 \%$ do total de lesões observadas na região do costado (C) do lado direito do corpo do animal e a 5,6\% dos 231 animais que tiveram lesões na região do costado (C) do lado direito do corpo quando os peões caíam do lado direito.

Esses dados mostram não haver nenhuma relação existente entre o lado de queda dos peões e o lado em que houve as lesões nos animais, o que pode ser comprovado aplicando-se o do teste do qui-quadrado, onde a associação entre o lado de queda dos peões e as lesões por esporas que ocorreram nos lados esquerdo e direito do corpo do animal e suas relações com a região do corpo em que ocorreram, não é significativo ( $p$-valor $=0,10$ ), onde o valor do quiquadrado calculado é 0,911 e 0,322 para os lados esquerdo e direito, respectivamente.

A maioria das lesões ocorreu na região do costado (C), quando observada a relação existente entre a mão que o peão segura durante a montaria (direita ou esquerda), com as lesões que ocorreram do lado esquerdo do corpo do animal. Foram feitas 20 observações de lesões na região do costado (C) 
SANTOS, A.L.Q. et al. Efeito dos equipamentos utilizados em touros de rodeio. PUBVET, Londrina, V. 5, N. 24, Ed. 171, Art. 1156, 2011.

quando os peões seguravam com a mão direita, indicando $14,9 \%$ do total de peões que seguraram com a mão direita e que os animais tiveram lesões na região do costado (C) do lado esquerdo; $71,4 \%$ do total de lesões observadas na região do costado (C) do lado esquerdo do corpo do animal e a $8,7 \%$ dos 231 animais que tiveram lesões na região do costado (C) do lado esquerdo do corpo quando os peões seguravam com a mão direita.

No entanto, observa-se que houve 11 observações de lesões do lado direito do corpo do touro, também na região do costado (C), quando os peões seguravam tanto com a mão direita quanto com a mão esquerda, indicando $8,2 \%$ e $11,3 \%$ do total de peões que seguraram com a mão direita e esquerda respectivamente, e que os animais tiveram lesões na região do costado (C) do lado direito do corpo do animal; representa $50 \%$ das lesões que ocorreram na região do costado (C) no lado direito do corpo dos animais quando os peões seguravam com a mão direita e o mesmo valor quando seguravam com a mão esquerda; e corresponde a 4,8\% dos 231 animais que tiveram lesões na região do costado (C) do lado direito do corpo quando os peões seguravam tanto com a mão direita como com a mão esquerda.

Esses dados mostram não haver nenhuma relação existente entre a mão que o peão segura durante a montaria e o lado em que houve as lesões nos animais, o que pode ser comprovado aplicando-se o do teste do qui-quadrado onde a associação entre a mão que o peão segura durante a montaria e as lesões por esporas que ocorreram nos lados esquerdo e direito do corpo do animal e suas relações com a região do corpo em que ocorreram, não é significativo ( $p$-valor $=0,10)$, onde o valor do qui-quadrado calculado é 0,705 e 0,794 para os lados esquerdo e direito, respectivamente.

Os resultados encontrados ao analisar o sentido do giro (anti-horário, horário ou reto) do touro durante a montaria, em relação às lesões que ocorreram no lado esquerdo do corpo dos animais, mostram que a maioria das lesões ocorreu na região do costado (C). Foram feitas 11 observações de lesões na região do costado (C) no lado esquerdo do corpo dos animais quando o touro girava no sentido horário, essas lesões correspondem a $14,3 \%$ do total de 
SANTOS, A.L.Q. et al. Efeito dos equipamentos utilizados em touros de rodeio. PUBVET, Londrina, V. 5, N. 24, Ed. 171, Art. 1156, 2011.

touros que giravam no sentido horário e que tiveram lesões na região do costado (C) no lado esquerdo do corpo; 39,3\% das lesões observadas na região do costado no lado esquerdo do corpo e 4,8\% dos 231 animais que tiveram lesões na região do costado (C) do lado esquerdo do corpo quando os touros giravam no sentido horário.

Observa-se que a maioria das lesões também ocorreu na região do costado (C) quando os touros giravam no sentido horário. Foram feitas 11 observações de lesões na região do costado (C) no lado direito do corpo dos animais quando o touro girava no sentido horário, que representam $14,3 \%$ do total de touros que giravam no sentido horário e que tiveram lesões na região do costado (C) no lado direito do corpo; $50 \%$ das lesões observadas na região do costado no lado direito do corpo e 4,8\% \% dos 231 animais que tiveram lesões na região do costado $(C)$ do lado direito do corpo quando os touros giravam no sentido horário.

Diante desses dados é possível observar que não existe nenhuma relação entre o sentido do giro dos touros durante a montaria e o lado em que houve as lesões nos animais, o que pode ser comprovado aplicando-se o do teste do qui-quadrado, onde a associação entre o sentido do giro dos touros durante a montaria e as lesões por esporas que ocorreram nos lados esquerdo e direito do corpo do animal e suas relações com a região do corpo em que ocorreram, não é significativo ( $p$-valor $=0,10$ ), onde o valor do qui-quadrado calculado é 0,993 e 0,132 para os lados esquerdo e direito, respectivamente.

\section{CONCLUSÕES}

Os dados obtidos na presente pesquisa permitem concluir que as cordas americanas utilizadas nos rodeios estudados não causam injúrias aos animais. Os sedéns não causam lesões aos animais e não entram em contato com os testículos durante a montaria, mas são capazes de causar incômodo aos animais, pois existe uma diferença estatisticamente significativa entre os momentos de antes e depois do aperto. 
SANTOS, A.L.Q. et al. Efeito dos equipamentos utilizados em touros de rodeio. PUBVET, Londrina, V. 5, N. 24, Ed. 171, Art. 1156, 2011.

As medidas das esporas mostraram haver uma diferença estatisticamente significativa, indicando não estarem padronizadas. No entanto, $68,8 \%$ dos animais não sofreram nenhum tipo de lesão.

A região do costado foi a que mais apresentou lesões, tanto do lado esquerdo $(9,5 \%)$ como do lado direito $(12,1 \%)$ do corpo do animal, o que pode ser devido a região de maior contato entre o animal e o peão durante a montaria. Não existe nenhuma relação entre o lado de queda dos peões, a mão que o peão segura durante a montaria (esquerda ou direita) e o sentido do giro dos touros durante a montaria (anti-horário, horário ou reto), com o lado em que ocorreram as lesões nos animais.

\section{REFERÊNCIAS BIBLIOGRÁFICAS}

BRASIL. Lei no 10.519, de 17 de Julho de 2002. Dispõe sobre a promoção e fiscalização da defesa sanitária animal quando da realização de rodeio e dá outras providências. Disponível em: <http://www.soleis.adv.br/>. Acesso em: 28 out. 2004.

CHEBADI, R. Z. Ação civil pública contra rodeios em Campinas: maus-tratos contra animais. Campinas-SP, 07 novembro 2000. Disponível em:

<http://www1.jus.com.br/pecas/texto.asp?id=162>. Acesso em: 25 out. 2004.

MARQUES, D. C., Criação de Bovinos, 7 ed., rev., atual. e ampl. Belo Horizonte: CVP Consultoria Veterinária e Publicações, 2002.

MEFFE, R., Tudo pronto para a prova decisiva. Globo Rural, n. 181, nov. 2000. Disponível em: <http://globorural.globo.com/barra.asp?d=/edic/181/rep_ rodeio. htm > . Acesso em: 21 ago. 2005.

MODALIDADES do Rodeio: Montaria em Touros, 2004. Disponível em:

<http://binhocowboysr.bliq.ig.com.br/>. Acesso em: 25 out. 2004.

MONTI, M. Projeto de Lei no 388, de 1999. Regulamenta a realização de rodeios, similares e dá providências correlatas. Apense-se ao projeto de Lei no 4.495, de 1998. Sala das Sessões, 23 de março de 1999. Disponível em: <http://www.miltonmonti.com.br/pl388-99.htm>. Acesso em: 20 out. 2004

O PORTAL do Rodeio no Brasil: equipamentos e acessórios obrigatórios nas montarias.

Disponível em: <http://www.rodeio.com.br/equipamentos.php>. Acesso em: 22 out. 2004.

PROFESSIONAL RODEO COWBOY ASSOCIATION PRCA Animal welfare: the care and treatment of professional rodeo livestock. Colorado Springs: Professional rodeo Cowboy Association, [1998?]. 20p.

PROVAS: Montaria em Touros. Disponível em:

<http://www.usuarios.asseta.net/coline/provas.html>. Acesso em 22 out. 2004. 
SÃO PAULO. Resolução SAA No 18 de 31 de março de 1998. Fixa normas complementares a serem observadas na promoção e fiscalização da defesa sanitária animal, a cargo da Secretaria de Agricultura e abastecimento, em especial quando da realização dos denominados "rodeios". Disponível em: <http://.coloradorodeio.com.br/reg01.php>. Acesso em: 24 out. 2000.

SERRA, R. A. A., Rodeio uma Paixão, Rio de Janeiro, Gryphus, 2000.

TANNENBAUM, J. Veterinary ethics: animal welfare, client relations, competition and collegiality. 2. ed. St. Louis: Mosby-year Book, 1995.

TORMEM, V. E., Interações do conjunto homem-animal-equipamentos em touros de rodeio, Uberlândia 1999. 77 f. monografia (Graduação em Medicina Veterinária). Universidade Federal de Uberlândia, 1999.

TORRES, G. C. V. Dicionário de termos zootécnicos e palavras correlacionadas com a produção animal. Salvador: Egba, 2000. p.130 e 259. 